\title{
Educational Reform and Policy Implementation in Hong Kong
}

\author{
Paul Morris and Ian Scott
}

(Published in Journal of Education Policy, 2003, Vol. 18, No. 1)

Research on implementation around the world indicates that many educational reforms designed to improve the quality of schooling have been more rhetorical than substantive in their impact on the organisation of schools and classrooms (Weiler, 1998; Fullan, 1991; Snyder, Bolin and Zumwalt, 1992). Schools and classrooms do change, but the extent and direction of change is not always consistent with the intentions of policy initiatives. The same applies in Hong Kong, where a substantial body of literature (see Morris 1996, Adamson et al, 2000) has documented the gap between the intentions of policy makers and their implementation in schools. The gap has been especially pronounced in those reforms attempting to change the prevailing styles of teaching and learning (Morris \& Morris, 2000). The reasons for this gap correspond to those described in the burgeoning international literature on policy implementation, which has attempted to identify the factors that serve as barriers to change. However, the traditional focus on the gap between educational policy and its implementation often results in what Goodson (2000) terms a form of 'implementationist myopia.' This is characterized by research which views policy as unproblematic and schools (and teachers) are evaluated from a technical perspective to assess how faithfully they implement the wisdom of the policy makers. The corollary of such a perspective is that teachers and schools are portrayed as the major impediments to change. Our initial premise is that the impact of educational reforms is influenced by a range of contextual factors and that, in the case of Hong Kong, it is the political context that has served as a powerful influence on both the nature of policy and its impact in schools.

We begin with a discussion of how implementation theory might contribute to our understanding of the difficulties of achieving educational reform in Hong Kong, in particular the limitations of what has largely been a 'top-down' approach to social programme implementation. In the second section of the paper, we seek an explanation of the reasons for this approach in the structure of the colonial regime and in its perennial problem of trying to reduce its legitimacy deficit while, at the same time, ensuring that it did not, in the process, create the conditions for social and political disruption. Our contention is that these difficulties resulted in symbolic education policies that promised great changes in teaching and learning but which, in reality, did little to disturb prevailing practice. In the third section of the paper, we provide some illustrations of how these education policies were formulated and implemented and with what results. In the final section, we analyse the policy implementation environment under the post-1997 government. We argue that it has inherited many of the constraints faced by the colonial regime and that it has, in addition, experienced the difficulties inherent in a disarticulated political system, difficulties which have adversely affected implementation. Education policies, in consequence, have remained largely at the level of good intentions; reform has proved elusive and, when it has been attempted, opposition has mobilised rapidly and sometimes successfully. 


\section{IMPLEMENTATION THEORY}

Those who write about implementation theory have long since questioned the notion that 'top-down' or control models of implementation alone can be used effectively to achieve social policy goals (Sabatier, 1986). Within centralized organizations, there are often problems with the transmission of policy intent from the most senior levels through the midlevel managers to the point of delivery. Many 'policies' remain impossible dreams that are incapable of implementation because of an absence of financial resources or qualified personnel or because they are insufficiently specific or because they are ambiguous. The middle manager is sometimes faced with the task of reconciling the irreconcilable, a situation that often produces outcomes characterised by 'grand pretensions, faulty execution, puny results' (Elmore, 1997:241). In addition, both the empirical evidence (Lipsky, 1980) and common sense suggest that the street-level bureaucrats who actually deliver the policy teachers, doctors and social workers, for example - will always be able to modify, or perhaps even to veto, instructions from central policy-makers should they choose to do so. The alternative 'bottom-up' approach, however, in which street-level bureaucrats might have significant inputs into policy-making, or a very decentralized system in which decisions would be made within the community, has never held much appeal for the Hong Kong government. Although, as we shall see, there has been some ambivalence within government about the mode of delivery, that is, the extent to which the state or market should dominate in educational provision, there has never been any question that ultimate control over policy should remain firmly in the hands of the government.

Faced with the fundamental systemic constraint of a 'top-down' orientation, Hong Kong policy-makers, who actually wanted to see their policy goals realized, might take either or both of two courses of action. The first would be to identify what Dyer (2000:58) has called 'veto points', institutional or other potential bottlenecks which would need to be overcome to allow policy to be implemented successfully. These veto points might include, for example, weaknesses in policy formulation or coordination at the centre, other organizational constraints such as problems at the point of delivery or conflicting policy objectives or the activities of powerful pressure groups. Many of the veto points necessarily involve the relationship between policy-makers and implementers. To resolve problems that might arise between them implies that a bargaining process is required to reach common ground. As Warwick (quoted in Dyer, 2000:56) puts it, 'effective implementation requires transactions between policy proponents, implementers and others whose support is necessary for action to happen'. Other theorists make similar points, advocating, for example, the need for explicit organization models for social program implementation which might include a bargaining model (Elmore, 1997). They assume, however, often with the American context in mind, that forums exist in which the parties come to the table, if not as equal partners, at least with the expectation that attempts will be made to identify an agreed path to achieve policy goals.

The Hong Kong government has shown little interest, either in colonial days or in its post-1997 manifestation, in pursuing such a transactional approach towards education policy 
implementation. Policy initiatives in education are justified after periods of wide public consultation in which the original view proposed by the government tends to prevail or by reference to the reports of 'wise men' employed by the government to suggest future directions. Subsequent policy changes are often made with relatively little consultation with those who are charged with implementing them. Interaction between policy-makers and implementers does, of course, occur but there seems very often to be an implied separation of roles. The government sees itself as responsible for the provision of resources, the formulation of programmes and the identification of key values in the education system. It does not, generally speaking, see its task as extending to the active management of the implementation process. That is seen to be the responsibility of the teachers and administrators who run the schools and other educational institutions and who are expected to follow government instructions. In the following sections, we suggest reasons why this approach has emerged. In summary, we believe that the major factors have been historically ambivalent attitudes towards state involvement in educational provision; the fear that opening forums and engaging in dialogue with active constituencies might compromise the government's position and lead to political confrontation; the concern that actively monitoring programmes might consume too many organizational resources; and the fragmentation of educational interest groups which makes it difficult for the government to deal with authoritative bodies on specific issues.

A second approach that might help to overcome the limitations of a 'top-down' orientation would be to seek to establish community agreement on values and then to translate them into policy. At its most general, such an approach attempts the impossible task of legislating 'motherhood' values into action, an enterprise that has been embraced by the post-1997 government in Hong Kong with predictably limited success (see Education Commission, 1999: 9-20). Even with consultation which was more extensive than that employed by its colonial predecessor, the post-1997 Education Commission was only able to secure agreement on vague generalities, such as the desirability of 'lifelong learning' (Kennedy, 2002). In a more specific form, however, it is possible to seek the agreement on values between policymakers and implementers on how a particular programme will proceed and what its objectives will be. These programmes would represent changes in target group behaviour but would be difficult, if not impossible, to achieve without the consent and active participation of those who would bring about the change. We have not been able to identify Hong Kong government education programmes where this specific approach has been adopted. The government has prompted an extensive discussion of values in education, perhaps with the hope of securing implementers' adoption of the values that it hopes to promote, but without the kind of managed implementation programme that might see those values translated into action.

Implementation theory tells us that, if the problems of a top-down approach are not addressed or modified in ways which take into account the importance of street-level bureaucrats, social policy implementation is unlikely to be successful. In the Hong Kong education context, the problems generated by its 'top-down' orientation have only been superficially addressed and policy has consequently remained largely symbolic. In the following section, we examine the constraints on implementation that are derived from its colonial legacy. 


\section{SYSTEMIC CONSTRAINTS ON IMPLEMENTATION UNDER COLONIALISM}

Colonial regimes, by their very nature, require top-down bureaucratic structures. The rule of the few over the many, pressures from the home government to ensure balanced budgets, and a shortage of qualified personnel all mean that the system is designed to ensure that the decisions of those at the top of the bureaucratic pyramid are faithfully and unquestioningly implemented by those at the bottom. Colonial regimes, especially in the prewar period, usually had limited social policy functions so that the specific problems associated with social programme implementation were not immediately experienced. In the Hong Kong case, the bureaucracy developed to the point where it had largely autonomous departments with efficient hierarchical structures carrying out a restricted range of functions. The strengths of such systems are that they do not require substantial investments in policymaking; resources can be devoted to the base of the implementation pyramid to ensure that the words of the senior bureaucrats do indeed become fact (Scott, 1987). The disadvantages of such systems are that they do not allow either for the extensive lateral coordination between departments nor for the vertical interaction with street-level bureaucrats that are necessary for effective social policy implementation. Despite repeated attempt to reform the system, power in Hong Kong still resides in a centralized bureaucracy which has been required to take on increasingly complex social policy initiatives.

Hong Kong's economic success has further exacerbated the tension between the government's avowedly laissez-faire philosophy and the provision of social policy outputs. The government itself attributes this success to keeping the bureaucracy small and its intervention in the economy and in society to a minimum. Social policy outputs are sometimes justified not as desirable ends in themselves but as a means towards a more productive, prosperous and healthy future (see Sutherland, 2002). Hong Kong, accordingly, is often seen to fit within the liberal or residualist model of welfare. In this model, welfare, broadly defined to include education, health and housing, is left principally to the market and is delivered through user payments for private schools, health care and housing. Governments intervene only to provide for those who cannot provide themselves and may still rely on nongovernment organizations to deliver services even if the government itself is providing the funding. There is little doubt that the residualist model is the Hong Kong government's preferred mode of welfare delivery. However, the territory's political legacy somewhat complicates the issue (McLaughlin, 1993:109; Gibson, 2002:37-46). The colonial regime in Hong Kong suffered from a substantial legitimacy deficit and welfare, cleverly distributed, represented a useful means of reducing that deficit. Hong Kong, in this sense, is closer to a conservative model of welfare in which the government itself provides for social services and increases its legitimacy by doing so (Esping-Andersen, 1990).

Unlike liberal welfare regimes, authoritarian regimes cannot legitimate their actions through the ballot box, a free press and a vigorous civil society. For much of its colonial history, Hong Kong had no elected element in its legislature, a largely uncritical press and a civil society that did not impact significantly upon the polity until the 1970 s. To justify its contention that it was a good government meant providing the highly prized social policy 
outputs -housing, education, and health care-that the population so clearly wanted. This posed a classical dilemma. Should the government deliver those services itself and maintain control and derive credit from the provision of these services? Or should it instead rely, as its laissez -faire philosophy prescribed, on the private sector and non-government organizations to do the work for it? Prior to the Second World War, only minimal services were delivered, very largely by private organizations with limited subventions from the government. After the war, there were signs of more state attention to welfare driven partly by the economic problem of the need for the land occupied by squatters, which led to the development of a resettlement and public housing programme, and partly by the political problem posed by the communist threat which led to more state control and provision of primary education. Until 1972, however, it would probably be accurate to place Hong Kong within the residualist model; the aim was to provide welfare for the most needy and for school children.

After the riots of 1966-67, notions of welfare gradually began to change. By the time MacLehose became governor in 1971, it had become clear both that the population greatly desired the social policy outputs that the government, fortunately, was able to fund and that their positive response to the provision of these goods reduced the possibility of social instability and increased the regime's legitimacy. More state welfare became increasingly identified with good government and, in providing these collective public goods, the regime gradually expanded its constituency of support. Public housing was eventually provided for almost $50 \%$ of the population, more places were available for secondary school students, more people claimed health and welfare benefits. That is not say that provision was ever entirely adequate or of high quality but the quantity of provision did provide a degree of regime support in the 1970s which was the envy of later governments who often sought in rather different times, to emulate the tactics of the MacLehose administration by expanding welfare provision.

The increase in welfare provision under the auspices of the state did not initially create major political problems for the colonial regime. The bureaucracy was very capable of providing the physical infrastructure in support of these new initiatives. New towns, more housing estates, more schools and hospitals were constructed with relative ease but often with little thought about what was going to happen once the buildings were actually occupied. The government had not arrived at the point where it was actively seeking to manage and implement new social programmes; the belief, rooted in previous history, was that welfare provision alone would be enough. This belief was reinforced in the 1970s by adverse experiences of what happened when the government did seek to deal directly and emphatically with teachers and students. In 1972, the government became involved in a dispute over the salaries of certificated teachers. Although the government eventually conceded on the issue, the dispute led to the formation of the Professional Teachers Union in 1974 (Leung, 1999:146). Its head, Szeto Wah, eventually became a leading figure in the democratic movement and was frequently at odds with the government. In 1978, for example, when the government closed the Precious Blood Secondary School and dismissed sixteen teachers, the union came out strongly in support of the dismissed teachers and gained considerable support as a consequence. The school was one of the more progressive secondary schools in Hong Kong and government action was seen to be retrogressive and a warning to teachers that traditional authority structures in schools were not to be challenged. 
The union, however, was able to generate support from other sections of the community and over 10,000 people attended a rally to oppose the government's decision (Leung, 1999:154). By 1982, the Professional Teachers Union was the largest single union in the territory.

In the transitional period to Chinese sovereignty (1984-1997), the government became very wary about intervening with the ways in which teachers and local administrators ran their programmes. Expanded provision alone was sufficient to generate the political support that regime required. Its legitimacy and its relationship with China was already so strained by the proposed post-handover political arrangements that it did not wish to risk the possibility of domestic confrontations over the implementation of its education policies. Thus the stage was set for the introduction of policies that were largely symbolic, designed to reassure the population that the quality of their children's education was constantly being improved, but lacking the substantive management and change processes that would see the programmes effectively implemented.

\section{SYMBOLIC POLICY}

A critical watershed in education policy occurred in 1978 with the introduction of nine years of compulsory education and the subsequent provision of places to year 11 for about $90 \%$ of the age cohort. After 1978, the educational policy agenda shifted away from a focus on providing more places to a concern for the quality of schooling. As with its housing policy, the government's capacity to expand the infrastructure and build more schools in a short period of time was a remarkable achievement. However, this was not paralleled by its capacity to develop a system of mass schooling designed to support Hong Kong's post industrial economy. Our concern in this paper is with the reforms, initiatives and innovations that attempt to improve the quality of schooling. Quality proved more difficult to deliver than quantity. Our argument is based on the premise that most educational policies and reforms promoted prior to 1997 that were designed to improve the quality of schooling served a primarily symbolic purpose. Their critical function was to demonstrate the government's concern to address educational issues. Where implementation could not be avoided, strategies were employed which involved compromise or capitulation in an attempt to maintain a consensus and minimize tension and conflict. The outcome was that the expectation and extent of change in schools was minimal. Thus, for example, the promotion of new subjects designed to broaden the curriculum (for example, Social Studies, Liberal Studies and a core curriculum in the 1970s); mother tongue language instruction; less didactic pedagogic styles (for example, the activity approach); and civic, sex and moral education were all essentially advisory and exhortatory statements of policy intentions. Their adoption was not mandatory and it was up to schools to decide whether to try to implement these changes. On the whole, there was little incentive to do so as the prevailing system of public assessment and rewards placed a premium on the maintenance of the status quo. Specifically, as far as pupils, parents and teachers were concerned the use of English and a focus on the high status academic subjects were more important. This perception was not inaccurate: a pupil who performed well in areas of the curriculum other than languages and mathematics was unlikely to go to a 'good' school or to progress to the end of secondary schooling. Many schools dropped subjects such as art, music and history from their timetable as these were seen to be 
peripheral to the task of preparing pupils for the high status public examinations (Morris 1997).

Although some officials were committed to the need for substantial changes to education policy and practice and although there was much encouragement from and heightened bureaucratic activity within the government to promote its reforms, there was limited support in the form of direct management and implementation of the policy initiative. There was, instead, a reliance on indirect policy actions, which often took the form of inducements such as the provision of extra teachers if schools adopted new policies and the creation of a new arm of the bureaucracy designed to support the reform. The result was a façade of compliance as schools attempted to obtain extra resources but no substantial attempt was made to monitor whether the policy (for example, using Chinese as the medium of instruction) was actually implemented. To do so would have produced evidence of the failure of government's policy and would have required appropriate action.

The primarily symbolic nature of policy was associated with two other features of the educational landscape: firstly, its tendency to introduce new reforms at a rapid rate, but not to substantially resource them. Essentially, if policy primarily served a symbolic function, then there were few constraints to promoting new reforms in rapid succession. Further, as educational problems became more central to the public's concerns and the policy agenda, so it became necessary for the government to be seen to be constantly responding to those concerns and to promote new initiatives. Teachers became jaded as they learnt to comply with, rather than attempt to implement, the latest short-lived government initiative. Civic education was a prototype of this pattern with Guidelines $(1985,1996)$ extolling its value but with little support for their implementation.

Secondly, when an educational problem was identified, the policy solution often involved an increase in bureaucratic activity and the creation by government of a new institution or organisation designed to address the problem. Examples of this are the creation of the Institute of Language Education (ILE) and The Standing Committee on Language and Research (SCOLAR), both designed to help address the problem of the medium of instruction in schools. As Mak (1996:406) has observed:

Reform measures tend to get translated into bureaucratic activities that keep everybody busy but amount to little real change... We are quick to espouse trendy ideas - autonomy, excellence, school effectiveness, child centred learning, reflective teaching etc. as if they were proxies for deeds, yet our mind set remains technically oriented. Thus, reform measures that intend to liberate end up engulfed in the old machine.

Consequently, a major barrier to the implementation of the current educational reforms is a long standing culture, a mixture of inertia and cynicism, that was established during the colonial period, and which continues. The continuing reform process also seems to result in considerable stress for teachers. A study of over 1000 teachers reported in October 2002 found that over $77 \%$ felt that 'frequently changing education policies caused the most pressure'(Chan, F., 2002). A consequence of inertia, cynicism and stress is that teachers 
continue to respond to reforms with a combination of suspicion, surface compliance and a 'wait and see' attitude fuelled by the assumption that any specific reform will soon be replaced or dropped. The government's desire to avoid conflict through the use of symbolic policy making was a relatively easy strategy in the more 'loosely coupled' areas such as those related to the school curriculum. Thus, both the Target-oriented Curriculum and the Bridge programme (which was intended to enable pupils to move from Chinese language to English medium instruction), foundered on the suspicion that those who introduced the reforms, whilst serious in their intent to support school improvement, would soon move on and their policies replaced by new ones. In other more directly coupled areas of policy, symbolic gestures alone were insufficient. For example, in determining the mechanism used to select pupils for secondary schooling, rhetoric could not suffice and real policy choices had to be made. However, in order to avoid conflict, or its corollary (for example, to maintain consensus), compromises were often made in an attempt to satisfy potentially competing groups of stakeholders. Thus, to satisfy the masses who desired access to good schools, an academic aptitude test was used to select pupils for secondary schooling. However, to ensure minimal disruption to the elite schools, pupils were placed in one of five bands according to their academic aptitude and schools were allowed to recruit a substantial proportion of pupils directly. The outcome was a seemingly meritocratic selection process for a highly segregated and elitist school system.

Whilst this might be viewed as anticipating political movements, such as the 'third way' and 'compassionate conservatism', its motive force in the 1970s had more to do with satisfying the competing demands of egalitarianism and elitism. The use of symbolic policy and compromises in education served the colonial government well but it was sometimes necessary to go one step further to avoid open conflict. The best example of this arose in the mid 1970s when Social Studies was developed as a new school subject integrating History, Geography, Economics and Civics. However, the Chinese History community objected strongly and portrayed the move as an attempt to dilute their subject and as a colonial plot to deny pupils access to their culture (Kan and Vickers, 2002). As the issue became public, the government capitulated and Social Studies emerged but without the inclusion of Chinese History.

The reason why the colonial government focused on the symbolic role of policy and avoided pushing implementation lay, as we have seen, in its tenuous legitimacy and inherent conservatism. The result was a desire to avoid any conflict, or forms of educational provision, which might subvert its role through the creation of conditions which would promote social or political disruption. To require schools to use Chinese or to require Chinese History to merge with (world) History would have been possible but would have resulted in conflict with powerful sectors of society, which could have threatened the stability of the government itself. Further, those groups who opposed reform (for example, the elite religious schools) were amongst the most ardent supporters of, and collaborators with, the colonial government. To pursue real change in schools would have required the use of more direct policy instruments (for example, mandates and sanctions). This would have invited public noncompliance: enforcement would have resulted in conflict with the providers of education, who were sensitive to the expectations of parents, pupils and the universities. In effect, the tacit compact between the government and the schools was that reforms were respectively 
symbolically promoted and symbolically adopted. Few real changes occurred and this satisfied the interests of both the government and the schools.

The government's policy on the appropriate medium of instruction in schools and the attempt to move the curriculum away from its focus on discrete academic subjects are the best examples of the symbolic nature of policy. Thus, for example, in the mid 1970s a 'common core' curriculum was introduced with Social Studies and Integrated Science as new subjects to replace the plethora of discrete subjects which made up the humanities and sciences. However, the new subjects were merely added to the list of available subjects and the majority of schools decided not to adopt Social Studies and to teach the separate sciences (Physics, Chemistry and Biology) from S3 onwards. There was much policy-making at the centre but little reform in the schools. In the 1980s, similarly, the government's attempt to broaden the sixth form curriculum by introducing Liberal Studies as a core subject was abandoned in the face of opposition from the universities. In another critical and highly contentious area, the government's promotion of Chinese medium instruction, which had been policy since the 1970s, the schools largely ignored central directives. Nothing was really done to enforce or constructively implement the policy. Only in 1998 did the post-colonial government move to require the majority of schools to implement the policy.

Most governments are inherently conservative as far as education is concerned for their fundamental goal is to socialize pupils in prevailing regime values and to prepare for the manpower needs of the economy. However, in the case of Hong Kong, many of the liberal sentiments that informed specific innovations (critical thinking, independent thinking and active citizenship) were fundamentally in tension with the maintenance of a colonial political system. Consequently, they were often promoted more as rhetorical slogans than as agendas for change. Where change did occur, it tended to be in micro-level areas and was limited by the political parameters which constrained broader reforms.

The legacy of the pre-1997 approach to policy making and its implementation, which was characterized by the primacy of symbolism, compromise and accommodation, lies in the enduring expectations, precedents and processes it has established. Basically, teachers are cynical about reform initiatives which are seen as short-term exercises in tokenism. Politicians view vocal opposition to any reform as sufficient to require its abandonment or substantial modification. For the post-handover government, which seems generally more determined than its predecessor to reform the education system and to enforce its policies, this legacy has been a major problem.

\section{THE POST-HANDOVER GOVERNMENT AND EDUCATIONAL REFORM}

While the post-handover government has inherited both the structural and legitimacy problems and the symbolic policies of the colonial regime, it has also encountered new difficulties which impede implementation and which have created new tensions. Two interrelated features are especially pertinent. The first is the emergence, since 1997, of a 'disarticulated' and a 'polyarchic' political system (Scott, 2000). The second is the highly destructive nature of Hong Kong's political culture. The two are related, but both seem to 
have been exacerbated by, rather than being the product of, the post-handover political context.

The key feature of a disarticulated political system is the conflict and lack of coherence between its component parts. In the post-handover system, this is a consequence of many different factors although the constitutional arrangements provided for under the Basic Law seem to have been particularly responsible for the friction which has developed between the executive and the legislature. The result has been that, in contrast to the publicly unified and centralized system which prevailed under colonialism, power has been dispersed, within what has become a polyarchic system, to many different centres of power. The executive retains overall control but it is itself fragmented and its ability to implement policy is constrained by legislators, pressure groups, and public opinion as well as by organized traditional street-level bureaucrats. Thus, in many areas of education policy, contradictory, or at least inconsistent, messages emerge from the Chief Executive, the various branches of the civil service, the Education Commission and other parts of the policymaking community. The facade of unity within the ranks of government has disappeared and power seems to be exercised and shared by a variety of groups within and outside the government. Thus, in the promotion of civic education, important differences relate to the emphasis on patriotism, nationalism and Chinese cultural identity on the one hand, and, on the other, to the quest for critical thinking and active and democratic citizenship. This lack of consensus could be a positive influence, as it might encourage schools to recognize the complex and competing purposes that civic education serves. Alternatively, the competition between the various sectors of government could result in each negating any attempt to develop a coherent policy and resource curriculum development in this area. Similarly, the Chief Executive's goal of achieving an 'all graduate and all trained' teaching profession has effectively been ignored as those intermediate bodies responsible for translating policy intents into actions have institutionalised arrangements to allow untrained graduates and non-graduates (termed 'permitted teachers') to be employed in schools. These features of Hong Kong's political culture, we argue, are especially destructive for educational reforms (Morris, 2002), especially in the post-1997 period when the government has attempted to implement policies more forcefully than its predecessor. The standard cycle of an educational reform typically has the following overlapping stages:

- the identification of an area of concern in education and its formulation as a 'problem' with the subsequent need for a policy to address it;

- public support for change is encouraged by strong criticism of the object of change (for example, language standards, problem solving) by government officials and/or of the perceived source of the problem (for example, curricula, schools, teachers, language standards, teacher education);

- a policy statement ( for example, an Education Commission report) spells out the need for change, describes the weaknesses of the status quo and identifies the broad policy intentions (for example, quality education, a knowledge society, lifelong/lifewide learning, enhanced teacher professionalism, the upgrading of teacher education) in a language which is essentially exhortatory; 
- policy intents are, to varying degrees, translated into specific policy actions of a direct or indirect nature.

The first three stages require that a clear problem should be identified. This often involves the identification of a specific group of providers who are the source of the problem and the target of the policy solution. Schools, teachers and teacher educators have all been identified at various stages by the government as the cause of one or more of the problems. This allows a clear policy solution to be identified (for example, testing teachers' language standards by attempting to 'benchmark' them) and ensures that little 'blame is directed at the government itself. This tendency for the government to base an education policy on a heavy duty criticism of its providers is linked to its lack of a political mandate.

Overall, however, these three phases engender a lively public debate and a broad consensus. Little tension or conflict emerges because they are couched in terms (for example, quality teaching, learning to learn, generic skills) that require no real decisions or choices to be made in terms of ideology or of resources and they tend to target relatively weak sectors of the community or institutions. However, the fourth stage, which involves the shift from statements of broad policy intentions to their translation into policy actions, generates more debate and concern as the implications for the relevant stakeholders emerge. Recent examples are the decisions to assess teachers' language proficiency in English (as one of the actions to upgrade the standard of language teaching); to merge the subjects of History and Chinese History (as an attempt to integrate the two and reduce the number of discrete school subjects); and to make some teacher educators redundant (as part of the upgrading of teacher education). Each of these policy actions resulted in an outcry from politicians and the Professional Teachers Union (PTU), who claimed that the actions were, respectively, an affront to teachers' professionalism, an attempt to denigrate the community's Chinese cultural identity, and an initiative which had produced unnecessary conflict and anxiety. The attempt to introduce more mother language teaching in schools has resulted in a somewhat different opposition coalition to government proposals. Despite support from many educational specialists and the PTU, the decision to reduce the number of English language medium schools provoked so many protests and petitions from parents, students and teachers that the government was forced, in part, to reverse its decision (Chan, E., 2002:276-79). In colonial times, this fourth stage of actually attempting to implement policy was usually avoided, given the symbolic function of policy and the desire to avoid conflict. More recently however there has been greater concern by the government to ensure implementation and move to the fourth stage. Consequently, the resulting conflict associated with the fourth stage has been more evident.

Clearly this cycle is not unique to Hong Kong for many governments have resorted to creating what Ball (1994) terms a 'discourse of derision' as a platform to launch a policy initiative. Vague intentions are often used to achieve a loose consensus. Subsequently, the tensions that are associated with the implementation of specific policy actions serves to highlight the fundamental dilemmas of schooling that face all societies. However, the strongly destructive character of this cycle and the tendency of the political classes to avoid promoting a constructive policy manifesto is distinctive to Hong Kong and may be explained by the nature of the political system. Only a minority of members of the Legislative Council 
are elected by universal suffrage, and of those a majority are members of the Democratic Party who have consistently won the elections and effectively received a mandate from the public. However, despite their political legitimacy, they have no power to introduce or implement policies and their sole influence on policy is essentially negative and often takes the form of blocking the necessary finances. Consequently, in the absence of this group of politicians being able to determine or substantially influence policy, their basic default role is that of an elected opposition which criticises the (unelected) government at every opportunity and occasionally blocks legislation. Hence, they will mete out criticism over the quality of education provided by the government at every opportunity, and subsequently criticize the government for taking any actions designed to address the problem they have identified. This scenario encourages political theatre and posturing, which is reinforced in the area of education by the strong connections between the Democratic Party and the largest public sector union in Hong Kong - the Professional Teachers' Union. In effect, any attempt to promote educational change that goes beyond a broad statement of intent is likely to become the victim of this destructive cycle. Essentially, the constant feature of the political context that has affected the implementation of policy involves the tenuous legitimacy of both the colonial and post-colonial governments. This has occurred in a community which on most indicators would be viewed as liberal and with a vibrant civil society and a government which is broadly tolerant and benevolent. It is against this background that the government's legitimacy is contrasted. A further critical difference between the pre- and post-handover periods involves the state of the economy. Whilst the colonial government had a tenuous political legitimacy, it obtained a form of economic legitimacy by virtue of the rapid growth of the economy and the community's rising affluence. The government was tolerated as it created an environment in which people could benefit from the growing economy. It could also, in a crisis, spend its way out of difficulties by distributing public goods, such as access to housing and education, more widely. In contrast, the post-handover government has been plagued by the effect of the Asian economic recession since 1997. This has limited its capacity to provide more subsidized public goods and it has removed a powerful source of legitimacy. Further, as whole areas of public policy, such as those related to the economy and defence, are largely determined by external forces, education, along with housing and social welfare, represents one field that can be usefully addressed by the Hong Kong government. Tung Chee Hwa himself has said that 'education policy is at the very core of our social policy' (Tung, 2000:17) and has given it very high priority on the policy agenda. The problem is that it is encumbered by a political system and internal constraints on implementation which make success unlikely in the present environment.

\section{CONCLUSIONS}

Implementation theory pays particular attention to the attempts of policy-makers to reach their objectives. The focus of the literature is principally on the constraints that face policy-makers, not on the overall design and problems of implementation inherent in the political system and the processes of policy-making within that system. In this article, we suggest that there are indeed problems in the relationship between policy-makers and implementers that have obstructed meaningful educational reform in Hong Kong. But we have also pointed to wider systemic constraints, problems relating to the legitimacy of the 
regime, the disarticulated political system and the destructive political culture that have meant that education policies have often been framed in largely symbolic terms beyond the competence of both education policy-makers to rectify. Education policy-making and its implementation in Hong Kong thus takes on a curious character. It is at once both a central concern and a neglected area; the more things change, the more they stay the same.

\section{REFERENCES}

Adamson, B. et al (eds.) (2000). Changing the Curriculum: The Impact of Reform on Primary Schooling in Hong Kong. Hong Kong: Hong Kong University Press.

Ball, S. (1994). Education Reform: A Critical and Post Structural approach. Buckingham: Open University Press.

Chan, E. (2002). Beyond Pedagogy: language and identity in post-colonial Hong Kong. British Journal of Sociology of Education, 23(2), 271-285.

Chan, F. (2002). Stress turns teachers' thoughts to self-harm. South China Morning Post, 7 October.

Dyer, C. (2000). Operation Blackboard: Policy Implementation in Indian Elementary Education. Oxford: Symposium.

Education Commission (1999). Education Blueprint for the 21 $1^{\text {st }}$ Century: Review of Academic System, Aims of Education Consultation Document. Hong Kong: Government Printer.

Education Department (1985). Guidelines on Civic Education in Schools. Hong Kong: Government Printer.

Education Department (1996). Guidelines on Civic Education in Schools. Hong Kong: Government Printer.

Education Department (1998). Syllabuses for Secondary School: Civic Education. Hong Kong: Government Printer.

Elmore, R.E. (1997). Organizational models of social program implementation. In Hill, M. (ed.) The Policy Process: A Reader. $2^{\text {nd }}$ Edition. Harlow: Prentice-Hall.

Esping-Andersen, G. (1990). The Three Worlds of Welfare Capitalism. Cambridge: Polity.

Fullan, M. (1991). The New Meaning of Educational Change. London: Cassell.

Gibson, C. (2002). The Mandatory Provident Fund: Welfare Capitalism in Hong Kong. Unpublished Honours thesis, Murdoch University. 
Goodson, I (2000). Foreword - Contextualizing the Curriculum. In Adamson, B. et al (eds.) Changing the Curriculum: The Impact of Reform on Primary Schooling in Hong Kong. Hong Kong: Hong Kong University Press.

Kan, F. and Vickers, E. (2002). One Hong Kong, Two Histories: 'history and 'Chinese history' in the Hong Kong school curriculum. Comparative Education 38(1).

Kennedy, P. (2002). Continuing Education in Hong Kong: Policy Rhetoric and Policy Reform. In Cribbin, J. and Kennedy, P. (eds.) Lifelong Learning in Action. Hong Kong: Hong Kong University Press.

Leung, J.Y. H. (1999). State and Society: The Emergence and Marginalization of Political Parties in Hong Kong. Unpublished PhD dissertation, University of Hong Kong.

Lipsky, M. (1980). Street-Level Bureaucracy. New York: Russell Sage.

Mak, G. C. L. (1996). Primary and Secondary Education. In Nyaw, M.K. and Li, S.M. (eds.) The Other Hong Kong Report. Chinese University Press, Hong Kong.

McLaughlin, E. (1993). Hong Kong: A Residual Welfare Regime. In Cochrane, A. and Clarke, C. (eds.) Comparing Welfare Regimes: Britain in International Context. London: Sage.

Morris, P. (1996). The Hong Kong School Curriculum: Development, Issues and Policies. $2^{\text {nd }}$ Edition, Hong Kong: Hong Kong University Press.

Morris, P. (1997). School Knowledge, the State and the Market: an Analysis of the Hong Kong Secondary School Curriculum. Journal of Curriculum Studies, 29(3).

Morris, P. (2002). Promoting Curriculum Reforms in the Context of a Political Transition: An Analysis of Hong Kong's experience. Journal of Education Policy, 17(1), 13-28.

Morris, P. \& Morris, E. (2000). Civic Education in Hong Kong: From Depoliticisation to Chinese Values. International Journal of Social Education, 14(1), 1-18.

Sabatier, P. (1986). Top-down and Bottom-up Approaches to Implementation Research: A Critical Analysis and a Suggested Synthesis. Journal of Public Policy, 6(1), 21-48.

Scott, I. (1987). Policy Implementation in Hong Kong. South-East Asian Journal of Social Science, 15(2), 1-19.

Scott, I. (2000). The Disarticulation of Hong Kong's Post-Handover Political System. The China Journal, No. 43, January. 
Siu, H. (1996). Remade in Hong Kong: Weaving into the Chinese Cultural Tapestry. In Liu, T. T. \& Faure, D. (eds.), Unity and Diversity: Local Cultures and Identities in China. Hong Kong: Hong Kong University Press.

Snyder, J., Bolin, F. \& Zumwalt, K. (1992). Curriculum Implementation. In Jackson P.W. (ed.), Handbook of Research in Curriculum. New York: Macmillan.

Sutherland, S. (2002). Higher Education in Hong Kong: Report of the University Grants Committee. Hong Kong: Government Printer.

Sweeting, A.E. \& Morris, P. (1993). Educational reform in post-war Hong Kong: planning and crisis intervention. International Journal of Educational Development, 13(3), 201-216.

Tung C. H. (2000). Serving the Community, Sharing Common Goals. Hong Kong: Government Printer.

Visiting Panel, (1982). A Perspective on Education in Hong Kong: Report by a Visiting Panel. Hong Kong: Government Printer.

Weiler, H. N. (1988). The Politics of Reform and Nonreform in French Education. Comparative Education Review, 32(3), 251-65. 